\title{
Towards next generation maggot debridement therapy: transgenic Lucilia sericata larvae that produce and secrete a human growth factor
}

Rebecca J. Linger', Esther J. Belikoff ${ }^{1}$, Ying Yan ${ }^{1}$, Fang Li ${ }^{1}$, Holly A. Wantuch ${ }^{1}$, Helen L. Fitzsimons ${ }^{2}$ and Maxwell J. Scott ${ }^{1 *}$ (i)

\begin{abstract}
Background: Diabetes and its concurrent complications impact a significant proportion of the population of the US and create a large financial burden on the American health care system. FDA-approved maggot debridement therapy (MDT), the application of sterile laboratory-reared Lucilia sericata (green bottle fly) larvae to wounds, is a cost-effective and successful treatment for diabetic foot ulcers and other medical conditions. Human platelet derived growth factor-BB (PDGF-BB) is a secreted dimeric peptide growth factor that binds the PDGF receptor. PDGF-BB stimulates cell proliferation and survival, promotes wound healing, and has been investigated as a possible topical treatment for non-healing wounds. Genetic engineering has allowed for expression and secretion of human growth factors and other proteins in transgenic insects. Here, we present a novel concept in MDT technology that combines the established benefits of MDT with the power of genetic engineering to promote healing. The focus of this study is to create and characterize strains of transgenic L. sericata that express and secrete PDGF-BB at detectable levels in adult hemolymph, whole larval lysate, and maggot excretions/ secretions (ES), with potential for clinical utility in wound healing.
\end{abstract}

Results: We have engineered and confirmed transgene insertion in several strains of $L$. sericata that express human PDGF-BB. Using a heat-inducible promoter to control the $p d g f-b$ gene, $p d g f-b$ mRNA was detected via semi-quantitative PCR upon heat shock. PDGF-BB protein was also detectable in larval lysates and adult hemolymph but not larval ES. An alternative, tetracycline-repressible pdgf-b system mediated expression of pdgf-b mRNA when maggots were raised on diet that lacked tetracycline. Further, PDGF-BB protein was readily detected in whole larval lysate as well as larval ES.

Conclusions: Here we show robust, inducible expression and production of human PDGF-BB protein from two conditional expression systems in transgenic $L$. sericata larvae. The tetracycline-repressible system appears to be the most promising as PDGF-BB protein was detectable in larval ES following induction. Our system could potentially be used to deliver a variety of growth factors and anti-microbial peptides to the wound environment with the aim of enhancing wound healing, thereby improving patient outcome in a cost-effective manner.

Keywords: Maggot debridement therapy (MDT), Platelet-derived growth factor (PDGF), Excretions/secretions (ES), Growth factor treatment, Diabetic foot ulcer, Tetracycline transactivator, Lucilia sericata, Wound healing

\footnotetext{
*Correspondence: mjscott3@ncsu.edu

'Department of Entomology, North Carolina State University, Campus Box

7613, Raleigh, NC 27695-7613, USA

Full list of author information is available at the end of the article
} 


\section{Background}

Diabetes is a global health care issue. Three hundredeighty-two million people were reported to have diabetes in 2013 (http://www.diabetesatlas.org). Additionally, the cost of diabetic foot ulcers to the American health care system was estimated to be $\$ 9-13$ billion in addition to care for diabetes in 2013 [1]. Maggot debridement therapy (MDT) is a cost-effective, FDA-approved treatment for diabetic foot ulcers [2, 3]. MDT commonly involves the application of sterile Lucilia sericata larvae to a non-healing wound to promote healing and decrease infection. MDT has been applied successfully in more than 20 additional medical conditions $[4,5]$.

MDT promotes healing in part through digestion and mechanical removal of necrotic tissue. Debridement is a critical component of effective wound healing [4, 6]. Enzyme application and mechanical debridement have been studied in clinical trials, but challenges such as expense and potential damage to healthy tissue stunt the large-scale effectiveness of these treatment options [7]. In contrast, larvae leave behind healthy tissue. Larvae have been shown to ingest fluorescent bacteria in vitro [8] as well as raise the $\mathrm{pH}$ of the wound environment via excretions and secretions (ES), which results in inhibition of bacterial growth [9]. Most of the in vitro studies found that ES was more effective at inhibiting growth of gram positive than gram negative bacteria [10]. Further, in one small vivo study, sterile maggots were found to be more effective at inhibiting growth of gram positive bacteria in infected wounds [11]. Specific factors and fractions have been identified within ES that exhibit antibacterial activity in vitro [12]. For example, the insect defensin homologue lucifensin was detected in the gut and salivary glands of L. sericata larvae and identified in wound washings from MDT patients [13]. Lucifensin exhibited antibacterial activity against a panel of Gram positive bacteria [13, 14]. Some data suggests expression and secretion of antibacterial factors by larvae is not constitutive, but induced by the wound environment [15-17]. The antibacterial mechanisms of MDT are free from the limitations of antibiotic resistance frequently seen in the clinic. Indeed, maggot debridement therapy has been shown to be effective in treatment of MRSA in vitro as well as in clinical case studies [18].

It is clear from these studies that larvae significantly alter the wound environment during MDT. Maggot ES may also alter the local inflammatory response. For example, L. sericata ES modulate neutrophil migration and adhesion and alter expression of pattern recognition receptor levels [19]. ES also increased the secretion of antiinflammatory cytokine IL-10, while inhibiting secretion of pro-inflammatory cytokines TNF-alpha and IL-12p40 [20].
In addition to the impact of MDT on the immune response in the wound, MDT also promotes wound healing through formation of granulation tissue [21, 22]. This could be a consequence of the physical action of the maggots in the wound, removal of dead tissue, change of wound $\mathrm{pH}$ and microbial killing [10]. In addition, there is some evidence that maggot ES could stimulate growth of human cells in the wound. ES was shown to stimulate fibroblast proliferation in culture [23] and hepatocyte growth factor (HGF) synthesis in 3T3 cells [24]. Further, increased HGF levels were measured in femoral vein blood of patient during MDT [24]. However, there is no evidence from randomized clinical trials that MDT shortens wound healing times [25]. This may reflect a limitation of the design of the trials [10] but highlights the need for further studies on the promotion of wound healing by maggots.

Studies have shown decreased concentrations of growth factors, including several isoforms of plateletderived growth factor (PDGF), in chronic wounds when compared to acute wounds [26, 27]. This evidence precipitated investigation into topical recombinant growth factor treatment as a means to promote healing in chronic wounds. Several growth factors were investigated, however molecular stability limited their success despite the use of gels, micropheres, and other conjugates. Nevertheless, after achieving some pre-clinical and clinical success, human PDGF-BB became the first FDAapproved recombinant cytokine growth factor [28].

The role of PDGF in wound healing is well established [29]. PDGF is a cationic hetero or homo-dimer consisting of a combination of alpha and beta subunit chains containing multiple intra- and inter-chain disulfide bonds. The subunits are produced in a pro form by endothelial cells, fibroblasts, immune system cells, and others [23]. The pro subunits dimerize in the endoplasmic reticulum into homo or heterodimeric combinations. The pro dimers are further processed via N-terminal modification, remodeling, and cleavage to a mature dimer form [30]. The mature dimers are secreted, where they interact with the extra-cellular matrix (ECM) and cell surface PDGF receptors. Via activation of the PDGF receptor and subsequently PI3 kinase and mitogen-activated protein kinase (MAPK), PDGF stimulates cell survival, fibroblast proliferation and chemotaxis, actin reorganization, and production and secretion of other growth factors, ECM constituents, and metalloproteases [29]. Because of the extensive role of PDGF in wound healing, clinical trials have been done investigating the utility of a topical gel (Becaplermin) containing recombinant human PDGF-BB produced in Escherichia coli [31]. Immunostaining of wounds treated with PDGF-BB showed increased fibroblasts, increased collagen fibril formation, and healing (as measured by decreased wound size) [32]. 
In one study, ulcer surface area and time to complete healing were both reduced significantly in patients receiving topical PDGF-BB along with standard wound care, however, the authors purposefully selected large, severe ulcers for inclusion in the study [33]. Similarly, other trials reported increased healing and/or reduced time to wound closure [34-41]. However, some trials did not find that topical PDGF treatment significantly improved wound healing [42-44]. The mixed outcomes could reflect the complexity of the wound healing process that involves mutiple factors, which supports the need for a therapy that combines multiple mechanisms to promote wound healing.

Here, we present a novel concept in MDT technology that combines the established benefits of MDT with the potential power of engineered maggots to promote healing. Genetically modified larvae engineered to secrete selected human growth factors or antibacterial peptides effective against Gram positive and Gram negative bacteria could have the potential to synergistically improve wound healing and result in shorter hospital stays. Given the low cost of rearing maggots, the technology is likely to be cost-effective compared to dressing gels containing recombinant proteins. The objective of this study is to determine if $L$. sericata can be engineered to conditionally express and secrete human PDGF-BB. PDGF-BB was selected because PDGF-BB made in E. coli is active and has been approved for use in wound treatment. However, we view this study as proof-of-principle for the future development of engineered $L$. sericata strains that express a variety of growth factors and antimicrobial peptides.

\section{Results}

Heat inducible expression of pdgf- $b$ RNA in transgenic $L$. sericata

A heat-inducible system was chosen for $p d g f-b$ expression as it provides several advantages. If fitness costs were observed, flies could be reared in non-permissive conditions in order to obtain sufficient numbers of larvae. Subsequently, during clinical application of larvae, the wound temperature would generate the permissive condition and induce $p d g f-b$ expression. We previously showed that the Lucilia cuprina hsp24 (Lchsp24) gene is strongly induced by heat shock in first and third instar larvae [45]. Further, several putative heat shock factor binding sites were identified within $500 \mathrm{bp}$ upstream of the transcription start site. Thus the Lchsp 24 promoter was selected to make the heat inducible $p d g f-b$ gene construct, $\mathrm{pB}[$ Lchsp24-pdgf-B] (Fig. 1a). The Lchsp24 gene fragment contained 1016 bp upstream of the start of transcription and $180 \mathrm{bp}$ of the $5^{\prime}$ UTR. The translation start codon was not included in the fragment. A gene fragment encoding the mature active form of $p d g f-b$ gene was synthesized with a codon usage optimal for expression in Lucilia. To facilitate secretion from $L$. sericata larvae, an amino terminal predicted signal peptide was included in the synthesized $p d g f-b$ gene. The signal peptide was identified in a venom peptide that is expressed in $L$. sericata larval salivary glands [46]. For polyadenylation of $p d g f-b$ transcripts, the gene construct contained the 3'UTR and 3' flanking DNA from a Lchsp70 gene. The Lchsp24-pdgf-b-pA gene construct was inserted into a piggyBac transformation vector used previously [47] (Fig. 1a.). The vector contains a ZsGreen marker gene under the control of a strong constitutive promoter (Lchsp83) for identification of transgenic larvae.

L. sericata CA06 embryos were injected with $\mathrm{pB}[$ Lchsp24-pdgf-B] DNA and a piggyBac helper DNA/ RNA mixture $[47,48]$. Four transgenic lines were obtained from $18 \mathrm{G}_{0}$ adults that developed from injected embryos. Two lines showed the predicted Mendelian inheritance for a single transgene (e.g. crossing heterozygotes with CA06 gave $50 \%$ fluorescent offspring). Molecular analysis (inverse PCR) also indicated that these two lines (PD1 and PD2) carried a single copy of the transgene. However, only the PD1 line was homozygous viable and fertile and so this line was selected for

a

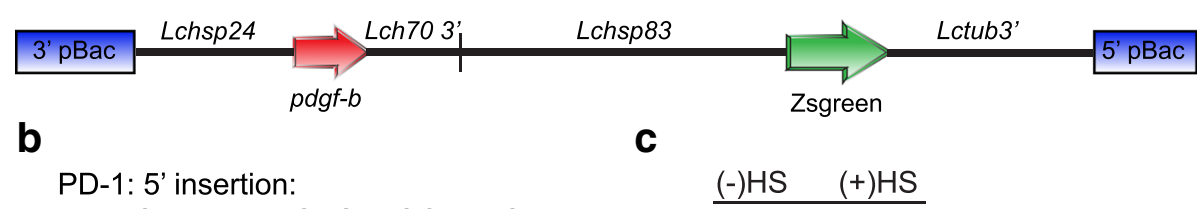

ITAAGAAAAATTGTGTTGCAAAGA

PDGF

Fig. 1 Heat inducible expression of pdgf-b mRNA in transgenic PD-1 L. sericata. a Schematic of heat-inducible pdgf-b gene construct in a piggyBac transformation vector with a ZsGreen marker gene. $\mathbf{b}$ Genomic DNA sequence adjacent to the 5' pBac end in the PD-1 transgenic line. The TTAA insertion site is underlined. $\mathbf{c}$ RT-PCR amplification of pdgf-b on total RNA obtained from first instar PD-1 larvae that had been given a heat shock $(+H S)$ or no heat shock $(-H S)$ 
further analysis. The nucleotide sequence adjacent to the the transgene was determined by inverse PCR (Fig. 1b). The transgene had inserted into a TTAA site, which is typical for piggyBac-mediated transformation [49].

To determine if $p d g f-b$ mRNA expression was inducible by heat shock at $37^{\circ} \mathrm{C}$, RT-PCR was performed on RNA isolated from PD-1 homozygous first instar larvae. A DNA fragment of the correct size was detected from the heat-treated $\left(37^{\circ} \mathrm{C}\right.$ for $\left.30 \mathrm{~min}\right)$ but not control larvae (Fig. 1c). This suggests that the PD-1 line provides a heat inducible system for $p d g f-b$ expression.

\section{Detection of PDGF-BB protein in PD-1 larval lysate}

We next sought to determine whether or not the human PDGF-BB protein was detectable in lysates of transgenic larvae. A commercial ELISA kit was chosen due to its high sensitivity (as low as $15 \mathrm{pg} / \mathrm{mL}$, according to the manufacturer). Further, ELISA assays detect native protein, while western blots detect linearized protein, allowing detection via antibodies against discontinuous as well as continuous epitopes, thereby further increasing likelihood of detection. For each assay, a positive control his-tagged recombinant human PDGF-BB was included, and yielded a positive signal within the kit standard range (data not shown). CA06 control (wt) and PD-1 larvae were subjected to a $3 \mathrm{~h}$ at $37{ }^{\circ} \mathrm{C}$ heat shock, then snap frozen. Lysates were normalized for total protein concentration and each sample was assayed in triplicate ELISA wells. PDGF-BB was undetectable in control CA06 lysate (Fig. 2a). While low basal levels of protein were detected in PD-1 larval lysate at the control temperature $\left(27^{\circ} \mathrm{C}\right)$, the PDGF-BB protein concentration increased 5 -fold with heat shock treatment (Fig. 2a). For any future clinical application it is important that the PDGF-BB protein is secreted from Lucilia cells and is present in larval ES. Thus we next heat-shocked larvae in ES collection buffer and collected the ES. However, PDGF-BB was not detectable in larval secretions (data not shown). Total protein concentration was approximtely 10-fold lower in ES samples compared to whole larval lysates. As a result, the amount of total ES protein loaded per ELISA well was one tenth to one half that of lysates. It is possible that PDGF-BB was present in the ES samples but below the level of detection of the assay. We next collected protein from adult hemolymph, reasoning that the protein concentration would be higher than larval ES. PDGF$\mathrm{BB}$ was detected in hemolymph isolated from adult PD1 flies after heat shock, albeit at a lower concentration than lysates (Fig. 2b.) These data suggest that the transgenic expression system is functional, and that PDGF$\mathrm{BB}$ is secreted into the hemolymph from cells in which it is expressed.

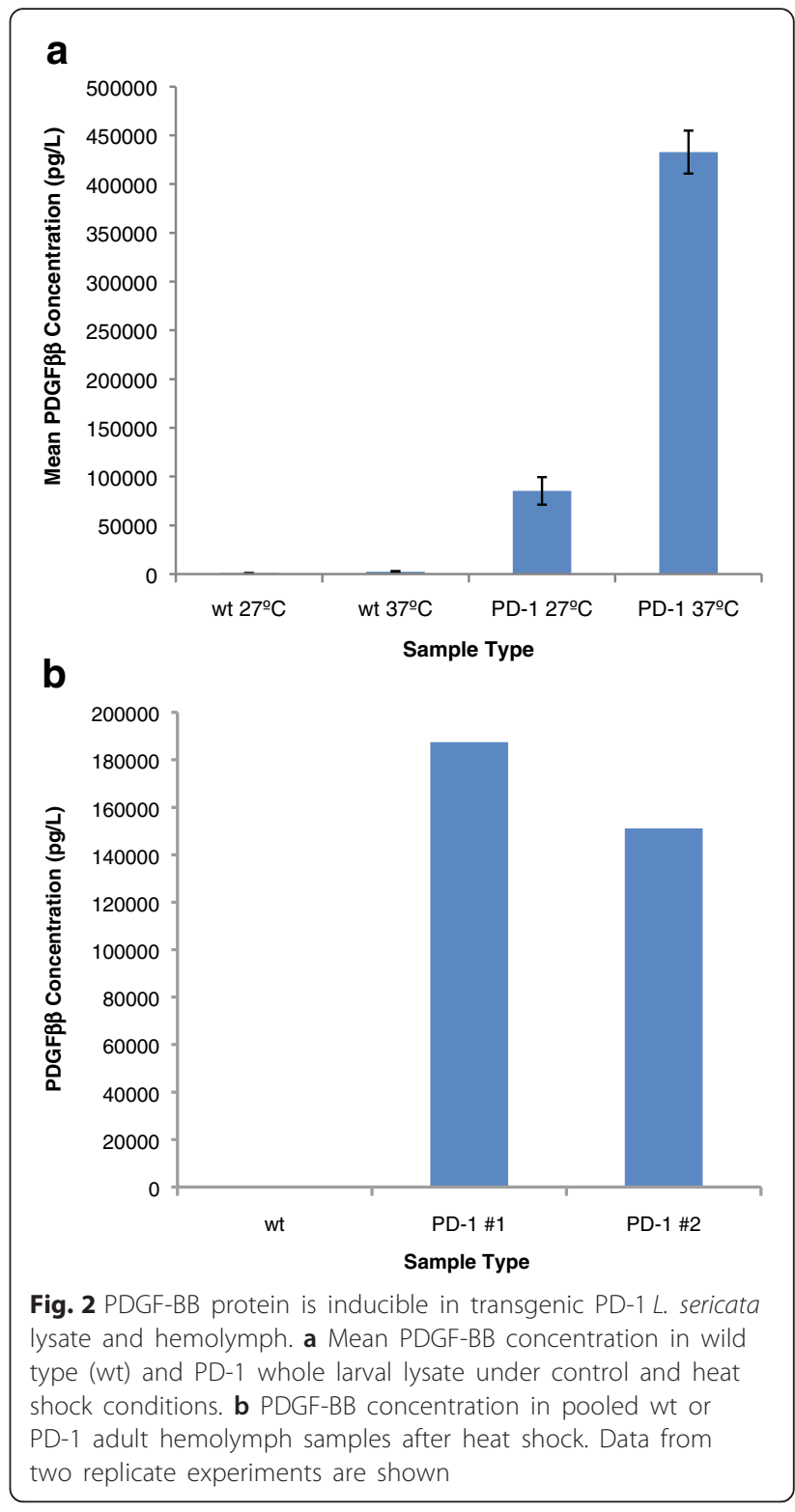

pdgf- $b$ RNA expression in transgenic $L$. sericata regulated by the tetracycline transactivator (tTA)

The above analysis suggested that higher levels of PDGF-BB expression were needed to produce detectable levels in larval ES. We had also previously shown that the "tet-OFF" system can lead to very high levels of gene expression in transgenic Lucilia [48]. The tet-OFF system is comprised of a tTA "Driver" construct and a tTA-responsive "Effector" construct (Fig. 3a). The $L$. cuprina hsp 83 promoter is a strong constitutive promoter in transgenic L. sericata [47]. Indeed, L. sericata larvae expressing DsRedex2 and ZsGreen under the control of this promoter appear light pink and greenish yellow respectively under white light (Fig. 3c). We reasoned that if the strong $h s p 83$ promoter was used to 

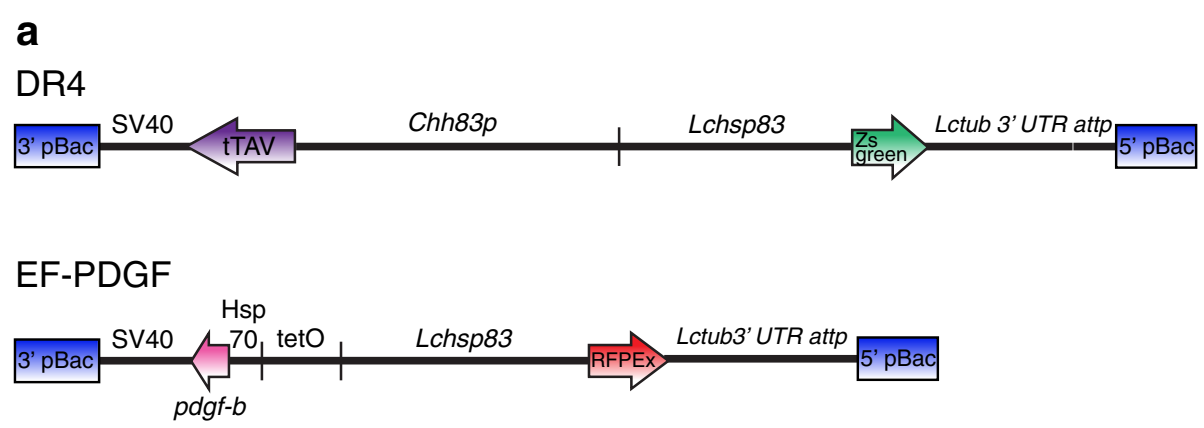

b

DR4: 3' Insertion: ITAATGATACAAAAACAATAATCC

EF-PDGF: 3‘ Insertion:

ITAAAATATTTTGGGAATCATCAT

C

DR4

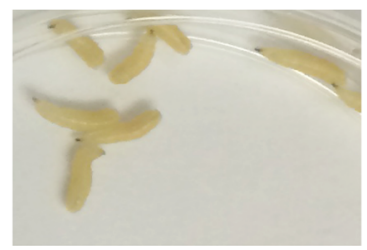

EF-PDGF
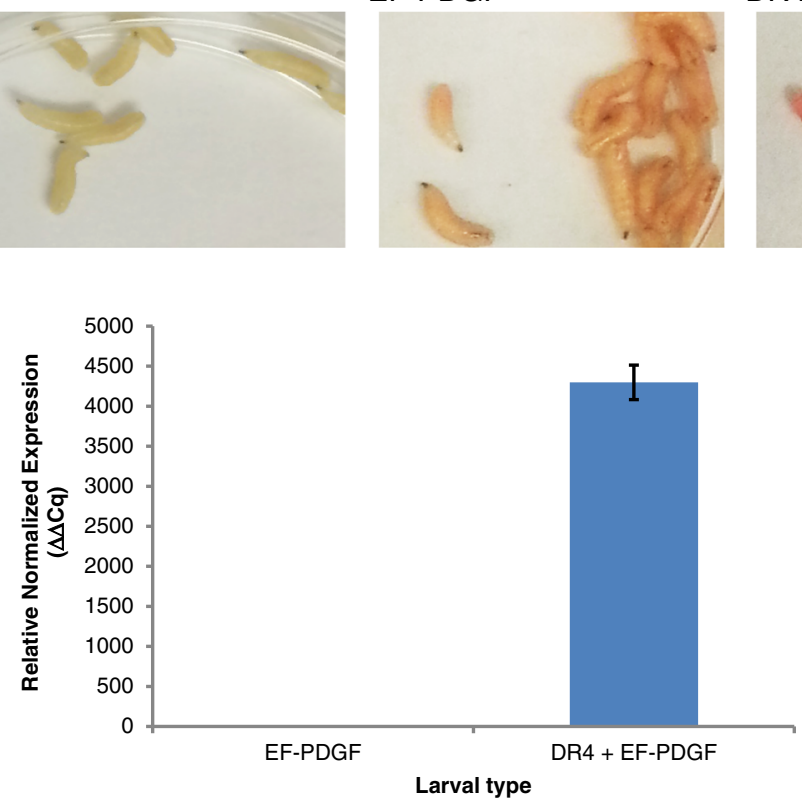

Fig. 3 tTA-mediated pdgf-b expression in transgenic L. sericata. a Schematic of the DR4 tTA driver and EF-PDGF tTA-regulated effector gene constructs in piggyBac transformation vectors. b Genomic DNA sequence adjacent to 3' pBac for each strain. c DR4\#14, EF-PDGF\#11, and DR4\#14 + EF-PDGF\#11 larvae under white light. $\mathbf{d}$ Relative expression of pdgf-b mRNA in control effector alone and tTA-driver plus effector larvae. qRT-PCR analysis was performed on RNA isolated from whole larvae and normalized to the $28 \mathrm{~s}$ rRNA reference gene

drive tTA expression, this would lead to very high levels of the effector, which in this study would be $p d g f-b$. Since the L. cuprina hsp 83 promoter was used for the marker gene, we isolated the $h s p 83$ promoter from a related blowfly, Cochliomyia hominivorax (Chhsp83). The start of transcription of the Chhsp 83 gene was determined by 5 ' RACE, using oligonucleotide primers based on a previously identified transcript [50]. The exon-intron arrangement was determined by PCR with genomic DNA template and primers based on the transcript. As for the Lchsp83 gene [45], the Chhsp83 gene contains one intron with the translation start codon at the beginning of the second exon. A PCR-based genome walking approach was used to obtain the nucleotide sequence of genomic DNA upstream from the start of transcription. The DR4 driver construct contains a $3 \mathrm{~kb}$ fragment from the Chhsp 83 gene upstream of the tTA coding region, followed by the SV40 polyadenylation sequence. The Chhsp 83 fragment includes 2225 bp of upstream flanking DNA, the 200 bp 5' UTR and the 586 bp first intron. The tTA translation start codon follows the Chhsp 83 intron. The Chhsp83-tTA gene cassette was cloned in a piggyBac transformation vector with a Lchsp83-ZsGreen marker gene. The EF-PDGF effector 
construct includes the tet $\mathrm{O}_{21}$-Lchsp 70 enhancer-promoter upstream of the $p d g f-b$ coding region and SV40 polyadenylation sequence. The tet $\mathrm{O}_{21}$-Lchsp 70 enhancerpromoter was used previously to achieve high levels of tTA gene expression in L. cuprina (autoregulated system) [48]. The $p d g f-b$ sequence with an $\mathrm{N}$-terminal signal peptide was the same as used above in the heat inducible system. The tetO-pdgf-b gene cassette was cloned into a piggyBac transformation vector with a Lchsp83-DsRedex 2 marker gene.

Transgenic DR4 and EF-PDGF lines were obtained by piggyBac-mediated transformation. For DR4, 9 lines were initially obtained from $137 \mathrm{G}_{0}$. However, the lines were weak and difficult to maintain. This is mostly likely because high levels of tTA protein are toxic to L. cuprina [48]. Consequently, only one line, DR4\#14, was maintained and this was propagated as a mixture of heterozygotes and homozygotes. DR4 had been injected into L. cuprina embryos as part of the effort to make male-only lines [51]. For this study, it was necessary to introgress the DR4 transgene into a $L$. sericata genetic background. This was done by crossing L. cuprina DR4\#14 males with MDLA $L$. sericata females. The offspring were then backcrossed for two generations with $L$. sericata females. The L sericata EF-PDGF\#11 line was obtained from $32 G_{0}$ and bred to homozygosity. The nucleotide sequence adjacent to the transgene insertion site was determined by inverse PCR (Fig. 3b).

To induce $p d g f-b$ expression, the DR4\#14 driver and and EF-PDGF\#11 effector lines were crossed and the larval offspring collected. In the presence of the antibiotic tetracycline, tTA is bound by tetracycline and rendered ineffective. In the absence of tetracycline, however, tTA is able to bind to tetO in the effector construct and activate $p d g f-b$ expression. Third instar larvae of the driver strain express ZsGreen marker, and appear yellow green in white light, while third instar larvae of the effector strain express the DsRedex2 marker and appear light pink. The progeny of this cross with both transgenes appear bright pink (Fig. 3c). This is most likely because tTA bound to tetO is also enhancing expression of the linked marker gene from the Lchsp 83 gene promoter. This was previously observed in larvae that overexpress tTA [48]. To confirm induction of $p d g f-b$ transcript, RNA was isolated and quantitative RT-PCR was performed. $p d g f-b$ transcript was readily detected in larvae that contain one copy of each of the DR4 and EF-PDGF transgenes. Control larvae (EF-PDGF only) had very low levels of $p d g f-b$ mRNA expression (Fig. 3d). In larvae that had both transgenes there was a greater than 4000 -fold increase in the level of $p d g f-b$ RNA (Fig. 3d).
PDGF-BB protein detection in whole larval lysate and ES from larvae heterozygous for the DR4 tTA driver and EF-PDGF effector

To determine if the larvae express and secrete PDGF$\mathrm{BB}$, ELISA assays were performed on ES samples collected from control EF-PDGF\#11 larvae and larvae with both the DR4 and EF-PDGF transgenes. As with the heat inducible system, PDGF-BB was readily detected in whole larval lysate from larvae with driver and effector (Fig. 4a). When the more dilute ES samples were analyzed, total protein concentration was again much less than for lysates (30-fold). Therefore, the amount of total ES protein per ELISA well was one tenth to one half that of lysates. However, PDGF-BB was detected in ES samples from larvae that have both DR4 and EF-PDGF

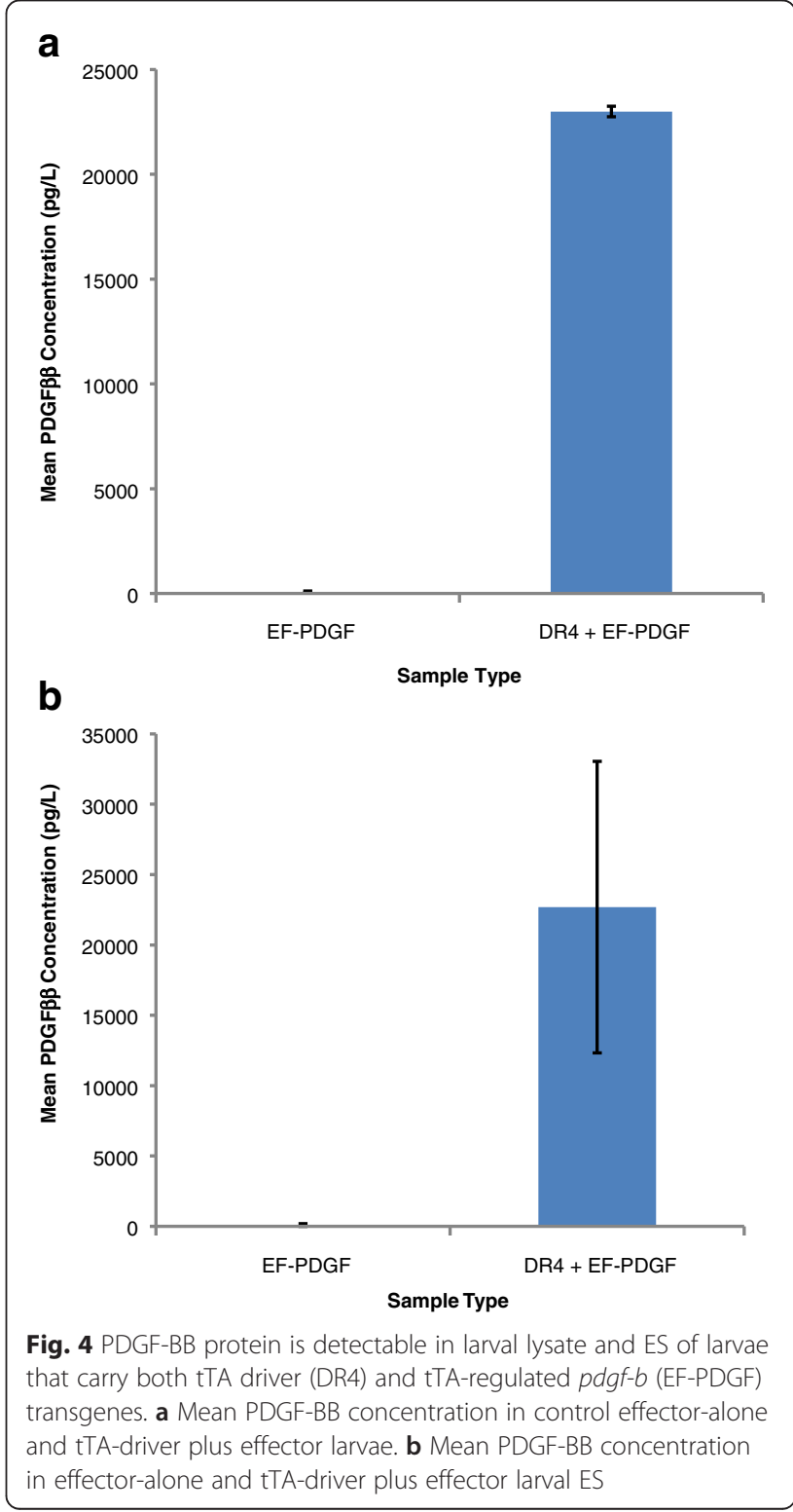


transgenes (Fig. 4b). Mean PDGF-BB concentration in ES was more variable between experiments than for whole larval lysates. Taken together, these data indicate that human PDGF-B is produced and secreted from third instar L. sericata larvae from a two-component transgene expression system.

\section{Discussion}

Proteins of human and other origins have been expressed in insect cells in culture for decades [52]. More similar to our study, human protein has also been expressed in tissue of insects using transient viral-based [53] and transgenic systems [54]. For example, Medin and colleagues reported detection of recombinant human adenosine deaminase, a primarily non-secreted protein, in Trichoplusia $n i$ larval lysate after injection of a baculovirus-mediated transgene [53]. Interest in expressing heterologous proteins in insect larvae has arisen from the desire for greater scale-up capabilities than is feasible using cells in culture. A more recent study demonstrated expression of a recombinant mouse antibotulinum antibody fragment (Fab) in Trichoplusia $n i$ larvae [55]. A secretory signal from Bombyx mori was utlilized to facilitate secretion of the protein product from larval cells, however, protein was purified from whole larvae. Lastly, secreted human proteins, including growth factors, have been expressed in Bombyx mori and purified from hemolymph as well as larval/pupal homogenate, and several of these proteins have proven functional in the veterinary clinic [56]. We show here for the first time that the translational and secretory mechanisms of the L. sericata larvae is capable of producing a human growth factor from our transgene expression systems, and that this protein is indeed detectable in hemolymph, larval lysate,and larval secretions. Further, we introduce the first human transgene expression in a larval host with potential for human clinical applications.

Two conditional systems were employed in this study, one regulated by temperature and the other by addition of tetracycline to the insect diet. The temperatureregulated system was chosen because $p d g f-b$ expression would theoretically increase upon application of the larvae to patient. Although $p d g f-b$ expression driven by the Lchsp 24 promoter was heat-inducible in whole larvae, we failed to detect PDGF-BB protein in maggot ES. Thus this conditional expression system would not be useful for any future clinical application. The D. melanogaster hsp 23 gene shows tissue-specificity and a cell-specific heat-shock response [57], therefore it's possible that Lchsp 24 promoter has low activity in Lucilia larval tissues that excrete/secrete proteins found in ES. Nevertheless, our finding that the Lchsp24 promoter is active and heat inducible could be useful for conditional expression of other proteins in blow flies. Further, PDGF-BB was detected in adult hemolymph after heat shock. This suggests that the pre-protein was likely correctly processed and secreted from Lucilia cells.

Using the two-component tet-OFF system, we have demonstrated that human PDGF-BB can be expressed in L. sericata larvae and detected in ES in an efficient inducible system. With this conditional system, larvae would be raised on diet without tetracycline to induce expression before wound application, thereby maximizing delivery of the secreted factor and healing potential. A strain could be potentially engineered with several different tetO-effector genes that would be co-regulated by tTA. For example, the effector genes would be other growth factors such as basic fibroblast growth factor [58] and/or antimicrobial peptides such as lucifensin [13] or Cecropin B [59]. The ES would be active against a broad spectrum of bacterial species as lucifensin is active against Gram positive bacteria [13] whereas Cecropin B is particularly active against Gram negative bacteria [59]. In the long term, clinicians might have at their disposal a panel of larvae expressing different factors for each individual wound based on the species of bacteria present in an infection, stage of wound healing, and level of inflammation.

The DR4 driver in our system may be further improved. The DR4 driver is not the best choice for building strains intended for clinical application, as high levels of tTA expression are toxic for Lucilia. A tTA driver employing a larval salivary gland-specific gene promoter would be advantageous [46, 60], as confining tTA expression to one tissue would likely have a lower fitness cost for the insect. Further, any effector protein induced by tTA would be secreted from the salivary gland. Alternatively, since larval excretions contribute to maggot ES, tTA could be expressed in the gut using a gut-specific promoter. The tet-OFF system could not be utilized in the clinic if tetracycline or a derivative was being used to treat an infected wound. If this proved to be problematic, the two-component GAL4-UAS system, widely used in Drosophila [61], could be considered for protein expression in Lucilia. With this system, it should be possible to achieve similar levels of protein expression as with the tet-OFF system, however expression would not be conditional. Lastly, with the identification of a $L$. sericata microbiome [62], a paratransgenesis approach [63] of utilizing a bacterial species to express a protein(s) of interest in the gut of $L$. sericata maggots could be considered.

As with any treatment modality, clinical application of genetically modified $L$. sericata would require regulatory approval. A potential challenge for the utility of modified MDT is patient attitude toward maggot application. However, several studies indicate that patients will accept MDT [64, 65]. Indeed, Steenvoorde 
et al., indicate that $89 \%$ of patients surveyed would undergo MDT again and $94 \%$ would recommend it to other patients [65]. Further, with the availability of polymer Biobags or pouches made of nylon or chiffon fabric [66], it may be possible to provide a liquidpermeable barrier when applying sterile genetically modified (GM) maggots to a wound, thereby making the treatment significantly more tolerable for opposing patients. It would also be anticipated that some patients would reject treatment with GM maggots given the public opposition to GM crops [67]. However, the GM maggots could be more acceptable, as the use of a fluorescent protein marker should facilitate thorough removal of maggots from a wound after treatment. The larvae could be readily visualized using goggles equipped with the appropriate filter sets [68].

Future studies are in order to further characterize the potential clinical utility of our system. Treatment of cultured fibroblasts with ES samples to measure MAPK activation, DNA synthesis, proliferation, and motility using an in vitro wound assay would confirm functionality of the secreted protein. Further, a rat wound healing model has been created [69] that would provide an excellent pre-clinical model.

\section{Conclusions}

Here we show robust, inducible production of human $p d g f-b$ RNA and PDGF-BB protein from two conditional expression systems in transgenic $L$. sericata larvae. With the heat-shock inducible system, PDGF-BB protein was detectable in hemolymph and whole larval lysate but not ES. The tTA-regulated system is more promising as PDGF-BB protein was detected in larval ES in addition to whole larval lysate from larvae raised on diet without tetracycline. Potentially, larvae could be engineered with several tTA regulated genes such that they secrete/excrete a variety of growth factors and/or antimicrobial factors with the aim of enhancing wound healing, thereby improving patient outcome. The International Diabetes Federation reports that $80 \%$ of people with diabetes live in low or middle income countries (http://www.idf.org/ diabetesatlas). Enhanced MDT may be a cost-effective solution for patients with less access to other treatment modalities.

\section{Methods}

\section{Insect rearing and germline transformation}

The CA06 and MD wild type strains of $L$. sericata were raised under similar conditions as described previously $[48,70]$. To make the MDLA mixed strain, 16 MD males were mated with 30 CA06 virgin females, the offspring collected and reared to adults. For heat shock experiments, MDLA or L. sericata PD1 eggs were placed on MYEA (50 g whole egg powder, $25 \mathrm{~g}$ instant non-fat milk powder, $12.5 \mathrm{~g}$ inactivated dry yeast, $7.5 \mathrm{~g}$ agar, $500 \mathrm{~mL}$ deionized water) at $27{ }^{\circ} \mathrm{C}$ overnight. First instar larvae were transferred to a new MYEA dish then heat shocked at $37{ }^{\circ} \mathrm{C}$ or left at $27{ }^{\circ} \mathrm{C}$ control for $3 \mathrm{~h}$. The larvae were collected and then washed with water using a filter, attached to an aspirator. Larvae were then snap frozen in liquid nitrogen and stored at $-80{ }^{\circ} \mathrm{C}$. Introgression of the DR4\#14 line into a $L$. sericata genetic background was done by crossing 125 DR4\#14 L. cuprina males with 80 MDLA virgin females. Male offspring were then crossed with MDLA virgin females for two generations. The male and female offspring allowed to breed freely to establish the line.

piggyBac-mediated germ-line transformation of $L$. sericata was as previously described $[47,48]$ using a mixture of Lchsp83-pBac DNA $(200 \mu \mathrm{g} / \mathrm{mL})$ and in vitro synthesized piggyBac RNA helper $(300 \mu \mathrm{g} / \mathrm{mL})$. Homozygous Lucilia individuals were selected at the wandering third instar larval stage based on fluorescence intensity and bred to create a stable line.

\section{Plasmid construction}

To make the $\mathrm{pB}[L c h s p 24-p d g f-\mathrm{B}]$ construct, firstly the Lchsp24 promoter [45] was amplified from L. cuprina genomic DNA with the primer pair 5'-GAGCTCCTCG AGTAGGGTGGGCAATTTTTTCTAATGCCCATTA-3' and 5'-GGATCCTGGATAGGCTTCACGGTCCAGTTC ATCGAT-3' and the fragment inserted into pBAC2 vector [47]. The Lchsp70 3' UTR and 3' flanking DNA [45] were amplified from $L$. cuprina genomic DNA with the primer pair 5'-AAGCTTAGTCAATCTCAATTTC ATTCC-3' and 5'-GCGGCCGCCTCGAGAATGATAT ATACAAGGA-3', and inserted downstream of the Lchsp 24 promoter. However, the Lchsp 24 promoter fragment retained the start codon, so this was removed by amplification of a portion of Lchsp24 without the start codon with the primer pair 5'-ATTATCATTATCTACT AGTTCAGTTCTAGTTAC-3' and 5'-ATTATCGGATC CCTCTTTGGTTTTCTTAAA ACG -3', then digested with SpeI and BamHI(blunt) and inserted into SpeI and AgeI(blunt) of pB[Lchsp24-pl-Lchsp70], effectively replacing the promoter with an identical fragment minus the ATG codon. A DNA fragment was synthesized by Genscript that encoded the human PDGF-B protein and a 20 amino acid signal peptide (MKSFLLVLFAFLAVFAFVQA) from an 87 amino acid venom peptide that was expressed in L. sericata salivary glands [46] and detected in larval ES (P.H. Nibbering, personal communication). The nucleotide sequence was optimized for expression in L. cuprina. The pdgf-B Genscript plasmid was digested with flanking Asp718 (blunt) and AvrII and inserted into NheI (blunt) and AvrII of 
pBAC2[Lchsp24-Lchsp70]. A PspOMI and partial SpeI digest of pB[Lchsp83-ZsGreen-tub.2] [47] released a $3.3 \mathrm{~kb}$ Lchsp83-ZsGreen-tub.2 cassette which was inserted into PspOMI and SpeI of pBSII KS+. The resulting pBSII KS+[Lchsp83-ZsGreen-tub.2] plasmid was digested with NotI and PspOMI and inserted into NotI digested $\mathrm{pB}[$ Lchsp24- pdgfB -Lchsp70] to create the final piggyBac transformation vector, $\mathrm{pB}[$ Lchsp24-pdgf-B].

To construct DR4 and EF-PDGF, the general strategy was to first assemble the driver or effector gene cassette in the cloning vector pBluescript II KS (-) and then excise the gene cassette by digestion with XhoI and NotI and clone into the unique XhoI and PspOMI sites in the piggyBac transformation vectors pB[Lchsp83-ZsGreen] [47] or pB[Lchsp83-DsRedex2] [48]. To assemble the effector construct, a fragment encoding PDGF-B with $\mathrm{N}$ terminal signal peptide was amplified from $\mathrm{pB}[$ Lchsp24-pdgf-B] using the primer pair 5'-TTATCATGAAGTCGTTCTTGTTGGTGTTG-3' and 5'-TGAAAGCTTAGGTCACGGGACGGGCGGCAG-3', digested with BspHI and HindIII, and ligated to pBSFL11 (Li et al. [48]) that had been digested with NcoI and HindIII. The effector gene cassette was then excised from the pBS-EF-PDGF plasmid and ligated with the $\mathrm{pB}[$ Lchsp83-DsRedex2] transformation vector.

For 5' RACE, total RNA was extracted from C. hominivorax embryos using TRI reagent (Sigma). polyA+ RNA was purified by oligo-dT chromatography (Sigma). 5' RACE-ready cDNA was prepared using the SMARTer RACE cDNA amplification kit (Takara) according to the manufacturers instructions. RACE-ready cDNAs were diluted in $20 \mu \mathrm{L}$ TE buffer (Clontech), and then $2 \mu \mathrm{L}$ was used for 5' RACE with the primer 5'-CAATTCACGCAA GAAAATCTCTTTGTTGGAATAGAAGGT-3'. "Genome walker" libraries were prepared from $C$. hominivorax genomic DNA using the Universal GenomeWalker kit (Takara) following the manufacturers instructions. PCR was then performed using the Chhsp 83 gene specific primers (GSP) 5'-GATCAACCACAATCTAATATATTAT AACTTTTTTCACTTTTCAGTT-3' and 5'-TTGTCT TTTCGCTCGCTTGGAAACTCTCGATGTAT-3'. The Chhsp83 gene promoter fragment for the DR4 construct was obtained by PCR amplification with genomic DNA template using the primers 5'-ATAGCGGCCGCTGTC ATTACTAGAGTTTAAGTTATAACAATTGTAT-3' and 5'-ACGCTGCAGATCTGGAAATACAATAGGAAAAAT AAAGTTAGCGAATT-3', then cloned into pGEM-T (Promega). The Chhsp83 promoter fragment was excised and ligated with pBS-FL1 that had been digested with NotI and PstI, essentially replacing the tetO-Dmhsp70 enhancer-promoter with the Chhsp 83 promoter. The Chhsp83-tTAv-SV40 gene cassette was then excised and ligated with the pB [Lchsp83ZsGreen] transformation vector.

\section{Genomic DNA isolation and inverse PCR}

Five to 6 frozen adults were ground to powder with a mortar and pestle under liquid nitrogen. Powder was dissolved in $4 \mathrm{~mL}$ fresh STE buffer $(50 \mathrm{mM}$ Tris- $\mathrm{HCl}$, $\mathrm{pH}$ 7.5, $100 \mathrm{mM} \mathrm{NaCl}, 10 \mathrm{mM}$ EDTA, pH 8). Two hundred $\mu \mathrm{L} 10 \%$ SDS and $8 \mu \mathrm{L}$ RNase A (Cat\# R4642-250MG Sigma Aldrich St. Louis, Missouri) were added and samples were incubated at $56{ }^{\circ} \mathrm{C}$. After 30 min, Proteinase K (Cat\# P2308-100MG Sigma Aldrich) was added to $100 \mu \mathrm{g} / \mathrm{mL}$ and the sample was incubated overnight at $56{ }^{\circ} \mathrm{C}$. Three $\mathrm{mL}$ phenol:chloroform:isoamyl alcohol [25:24:1] (Cat\#P2069, Sigma) was added and samples were rotated $10 \mathrm{~min}$ at $12 \mathrm{RPM}$ at $22{ }^{\circ} \mathrm{C}$. Samples were then centrifuged $10 \mathrm{~min}$ at $1000 \mathrm{~g}$ at $4{ }^{\circ} \mathrm{C}$. The aqueous layer was transferred to a new tube and the extraction was repeated. One tenth volume $3 \mathrm{M}$ sodium acetate, pH 5.2 and 2 volumes cold $100 \%$ ethanol were added and mixed. The samples were incubated at $-20^{\circ} \mathrm{C}$ for $1 \mathrm{~h}$ and centrifuged $30 \mathrm{~min}$ at $7200 \mathrm{~g}$ at $4{ }^{\circ} \mathrm{C}$. The supernatant was removed from the pellet, which was washed with $1 \mathrm{~mL}$ cold $75 \%$ ethanol. The pellet was air-dried $10 \mathrm{~min}$ before resuspension in 50-100 $\mu \mathrm{L}$ TE Buffer. To determine genomic sequence flanking the transgene insertion, inverse PCR was performed with MboI, Taq $\alpha \mathrm{I}$, and MspI-digested genomic DNA templates as described previously [48, 71].

\section{RT-PCR and qRT-PCR}

RT-PCR was performed with cDNA template from total RNA isolated from larvae as described previously [72]. The $p d g f-b$ primer pair used were PDGF-F (5-' ATG AAG TCG TTC TTG TTG GTG TTG TTC GCC TTC TTG GCC GTT-3') and PDGF-R (5'- CCG GAG TTT AAA CCC TAG GCG CGC CAT GAG CTC AAG CTT TCA TTA-3'). For RNA isolation for quantitative RT-P CR (qRT-PCR), 5-6 frozen larvae were homogenized in $500 \mu \mathrm{L}$ of Trizol (Cat\#15596026 Life Technologies/ Thermo Fisher Scientific Waltham, Massachusetts) in a $1 \mathrm{~mL}$ glass homogenizer that had been previously baked at $200{ }^{\circ} \mathrm{C}$ overnight. $100 \mu \mathrm{L}$ of chloroform was added, and samples were shaken for $15 \mathrm{~s}$ and allowed to incubate at $22{ }^{\circ} \mathrm{C}$ for $15 \mathrm{~min}$. Samples were centrifuged at $18,000 \mathrm{~g}$ for $15 \mathrm{~min}$ at $4{ }^{\circ} \mathrm{C}$. The aqueous layer was mixed with an equal volume cold RNase-free $70 \%$ ethanol, mixed, and loaded on a Qiagen RNeasy Mini Kit column (Cat\#74104 Qiagen Venlo, Netherlands). The purification was performed according to the kit protocol, including the optional on-column DNase digest using the RNase-free DNase set (Cat\#79254 Qiagen). A subsequent in-solution DNase digest was performed to eliminate residual DNA, followed by a second round of column purification. cDNA was synthesized from $3.5 \mu \mathrm{g}$ of DNase treated RNA using Superscript III (Cat\#18080400 Invitrogen) according to manufacturer's instructions. Random hexamers were used as primers. Negative 
control reactions containing water instead of enzyme mix were performed to confirm the absence of DNA contamination.

PDGF qPCR primers were designed using Primer3: hPDGF F (5'- GAAATTGTGCGTAAAAAGCCCATTT-3') and hPDGF R (5'- AACAGTTTCACATTTACAGGCC AAA-3'). Primers were tested for efficiency by creating a dilution series of cDNA. Template was pipetted into quadruplicate wells of a 384 well optical plate (Cat\#4309849 Applied Biosystems). Thermo Maxima SYBR Green/ Rox qPCR Master Mix 2X (Cat\#K0221 Thermo Fisher Scientific Waltham, Massachusetts) was added to primers to create a master mix, which was dispensed into wells via a multi-channel pipet. The plate was sealed (Cat\#4311971 Applied Biosystems), mixed, then centrifuged $1 \mathrm{~min}$ at RT at $1600 \mathrm{~g}$. The qPCR run was performed on a BioRad CFX384 C1000 Touch Thermocycler (BioRad Hercules, CA) using the following program: $95{ }^{\circ} \mathrm{C} 10 \mathrm{~min},\left[95{ }^{\circ} \mathrm{C} 15 \mathrm{~s}\right.$, $\left.60{ }^{\circ} \mathrm{C} 60 \mathrm{~s}, 40 \mathrm{x}\right]$. Data acquisition was performed on the anneal/ extension step. Primer efficiency was determined by plotting the $\log$ of the starting template dilution on the $\mathrm{X}$-axis and the mean $\mathrm{Cq}$ of the quadruplicate replicates on the Y-axis. The slope of the best fit line was used in the following equation to calculate efficiency: $\left[\right.$ Efficiency $\left.=-1+10^{(-1 / \text { slope })}\right]$. Primers were accepted if efficiency was $90-105 \%$ and re-designed if efficiency fell outside this range.

For measurement of relative transcript levels, cDNA templates were diluted 1:4 with nuclease-free water then pipetted into quadruplicate wells of a 384 well optical plate for each primer set, hPDGF and the $28 \mathrm{~s}$ rRNA reference gene. The $28 \mathrm{~S}$ rRNA primer pair were Lc-28SF (5'-ACCACTGTTCACACGAAACCCTTC-3') and Lc-28 SR (5'-ATCTCGGTTGGATTTTAAACTTTGAAA-3'). The $\mathrm{qPCR}$ protocol was performed as above. Analysis of delta delta $\mathrm{Cq}$ was performed using BioRad CFX Manager. Mean Cq value was found for each set of 4 replicate wells. The reference gene was utilized to calculate $\Delta$ Cq. The EF-PDGF control was chosen as the calibrator sample and set to 1 . The bar graph represents $\Delta \Delta \mathrm{Cq}$ (relative normalized expression), with error bars representing standard error of the mean for the replicate values.

\section{Protein analysis}

With the PD1 line (Lchsp24-pdgfb), prior to hemolymph collection, adult flies were heat shocked at $37{ }^{\circ} \mathrm{C}$ for $2 \mathrm{~h}$ with access to water and allowed to recover at room temperature for $3 \mathrm{~h}$. Flies were anesthetized by exposure to carbon dioxide and then one wing was removed. The hemolymph was squeezed into a capillary tube pre-filled with a small amount of cold hemolymph collection buffer $(10 \mathrm{mM}$ EDTA $\mathrm{pH} 7$ in $1 \mathrm{X}$ phosphate-buffered saline (PBS) + 1X Protease inhibitor cocktail (Cat\# P2714, Sigma-Aldrich, St. Louis, MO) on ice. Samples were centrifuged $2 \mathrm{~min}$ at $10,000 \mathrm{~g}$ at $4{ }^{\circ} \mathrm{C}$. Supernatant was transferred to a new tube. Multiple adults were pooled for one sample. Samples were stored at $-80{ }^{\circ} \mathrm{C}$.

For offspring of the cross between DR4 driver and EFPDGF effector, third instar larvae were sorted by fluorescence and rinsed with water on a vacuum funnel with gentle suction. Larvae were briefly placed on a Kim Wipe to remove excess moisture before being placed in Eppendorf tubes and snap frozen in liquid nitrogen. For ES collection, larvae were processed as above and then placed into wells of a 12-well flat-bottomed polystyrene tissue culture plate. Six or 50 larvae were added per well. Two hundred $\mu \mathrm{L}$ (for 6 larvae) or $1 \mathrm{~mL}$ (for 50 larvae) of ES collection buffer (Ringer Solution $[0.120 \mathrm{mM} \mathrm{NaCl}$, $1.5 \mathrm{mM} \mathrm{CaCl}_{2}, 5 \mathrm{mM} \mathrm{KCl}, \mathrm{pH}$ 7.4, filter sterilized] + 1X Protease inhibitor cocktail) was added per well, and wells were sealed with an adhesive plate sealer. After $40 \mathrm{~min}, \mathrm{ES}$ was removed and centrifuged at 21,000 $\mathrm{g}$ for $30 \mathrm{~min}$ at $4{ }^{\circ} \mathrm{C}$. Supernatant was transferred to a new tube and stored at $-80{ }^{\circ} \mathrm{C}$, and debris pellet was discarded. Frozen larvae were lysed on ice in cold gentle lysis buffer [73] using $1 \mathrm{~mL}$ glass homogenizers. Following homogenization, lysates were centrifuged at $15,000 \mathrm{~g} 15 \mathrm{~min}$ at $4{ }^{\circ} \mathrm{C}$. Supernatant was transferred to a new tube and stored at $-80{ }^{\circ} \mathrm{C}$, while debris pellet was discarded.

Total protein concentration was determined for lysates and hemolymph using the Pierce BCA Protein Assay Kit (Cat\#23227, Thermo Fisher, Rockford, IL) and for ES using Quickstart Bradford 1X Dye Reagent and Quickstart Bovine Gamma Globulin Standard (Cat\# 500-0205 and 500-0208, BioRad, Hercules, CA). The hPDGF-BB Quantikine ELISA kit was purchased from R\&D Systems (Cat\# DBB00) and assay was performed according to kit protocol. Lysate and ES samples were assayed in triplicate wells, containing $150 \mu \mathrm{g}$ and $15-60 \mu \mathrm{g}$ protein per well respectively. Eighty $\mu \mathrm{g}$ of total protein from each hemolymph sample was assayed per well. Recombinant His-tagged human PDGF-BB (Cat\# ab73231, Abcam, Cambridge, MA) was assayed on each ELISA run and provided a positive, in-range control for the integrity of the kit. Sample concentrations were extrapolated or interpolated from a standard curve constructed from the $\log$ PDGF-BB concentration $(\mathrm{pg} / \mathrm{L})$ on the $\mathrm{X}$-axis and the log mean optical density reading (OD) on the Y-axis. Error bars represent standard error of the mean for the replicate values.

\section{Ethics approval and consent to participate}

"Not applicable" as this study did not involve any animal or human data or tissue. 


\section{Consent for publication \\ "Not applicable".}

\section{Availability of data and material}

The GenBank accession numbers for the plasmids made in this study are:

\section{pB[Lchsp24-pdgf-B]: KT897708 \\ DR4: KT897710 \\ EF-PDGF: KT897709}

\section{Abbreviations}

CDNA: Complementary DNA; Ch: Cochliomyia hominivorax; Cq: Quantification cycle; ECM: Extra-cellular matrix; EDTA: Ethylenediaminetetraacetic Acid; ELISA: Enzyme-linked immunosorbent assay; ES: Excretions/secretions; FDA: Food and Drug Administration; GM: Genetically modified; GSP: Gene specific primers; h: Hours; HGF: Hepatocyte growth factor; hPDGF: Human Platelet-Derived Growth Factor; Hsp: Heat shock protein; IL-\#: Interleukin; kb: Kilobase; Lc: Lucilia cuprina; Ls: Lucilia sericata; MAPK: Mitogen-activated protein kinase; MDT: Maggot debridement therapy; mRNA: Messenger RNA; MRSA: Methicillin resistant Staphylococcus aureus; MYEA: Milk, yeast, egg, agar larval media; OD: Optical density; pBac: piggyBac; PBS: Phosphate-buffered saline; PCR: Polymerase chain reaction; PDGF-B: Platelet-Derived Growth Factor Beta; RACE: Rapid Amplification of cDNA Ends; rRNA: Ribosomal RNA; RT: Reverse transcriptase; s: Seconds: SDS: Sodium dodecyl sulfate; TE: Tris- EDTA; Tet: tetracycline; tetO: Tetracycline operator; TNF-alpha: Tumor necrosis factor alpha; tTA: Tetracycline transactivator; $\mu \mathrm{g}$ : Microgram; UTR: Untranslated region

\section{Competing interests}

The authors declare that they have no competing interests.

\section{Authors' contributions}

RJL carried out the experiments and drafted the manuscript. EJB participated in the experimental design and carried out the genetic experiments, YY developed the DR4 lines, FL, HAW and HLF participated in the design, made and analyzed the Lchsp70-PD1 transgenic lines, MJS conceived of the study, and participated in its design and coordination and drafted the manuscript. All authors read and approved the final manuscript.

\section{Acknowledgements}

We thank Aaron Tarone for comments on the manuscript. RJL, FL and HAW were supported by startup funds to MJS from NCSU, EJB's effort on this project was supported by NCSU, YY work on the DR4 lines was supported by a grant from the Panama-United States Commission for the Eradication and Prevention of Screwworm (COPEG).

\section{Author details}

${ }^{1}$ Department of Entomology, North Carolina State University, Campus Box 7613, Raleigh, NC 27695-7613, USA. ${ }^{2}$ Institute of Fundamental Sciences, Massey University, Palmerston North, New Zealand.

Received: 23 October 2015 Accepted: 17 March 2016

Published online: 22 March 2016

\section{References}

1. Rice JB, Desai U, Cummings AK, Birnbaum HG, Skornicki M, Parsons NB. Burden of diabetic foot ulcers for medicare and private insurers. Diabetes Care. 2014;37(3):651-8

2. Wayman J, Nirojogi $V$, Walker A, Sowinski A, Walker MA. The cost effectiveness of larval therapy in venous ulcers. J Tissue Viability. 2000;10(3):91-4.

3. Thomas S, Jones M. Wound debridement: evaluating the costs. Nurs Stand. 2001:15(22):59-61.

4. Chan DC, Fong DH, Leung JY, Patil NG, Leung GK. Maggot debridement therapy in chronic wound care. Hong Kong Med J. 2007:13(5):382-6.

5. Sherman RA, Mumcuoglu KY, Grassberger M, Tantawi TI. Maggot therapy. In: Grassberger M, Sherman RA, Gileva OS, Kim CMH, Mumcuoglu KY, editors. Biotherapy - history, principles and practice: a practical guide to the diagnosis and treatment of disease using living organisms. Dordrecht: Springer; 2013. p. 5-29.

6. Sherman RA, Hall MJ, Thomas S. Medicinal maggots: an ancient remedy for some contemporary afflictions. Annu Rev Entomol. 2000;45:55-81.

7. Jeffcoate WJ, Price P, Harding KG, International Working Group on Wound $\mathrm{H}$, Treatments for People with Diabetic Foot U. Wound healing and treatments for people with diabetic foot ulcers. Diabetes Metab Res Rev. 2004;20 Suppl 1:S78-89.

8. Lerch $\mathrm{K}$, Linde HJ, Lehn N, Grifka J. Bacteria ingestion by blowfly larvae: an in vitro study. Dermatology. 2003;207(4):362-6.

9. Robinson W. Ammonium bicarbonate secreted by surgical maggots stimulates healing in purulent wounds. Am J Surg. 1940;47:111-5.

10. Sherman RA. Mechanisms of maggot-induced wound healing: what do we know, and where do we go from here? Evid Based Complement Alternat Med. 2014;2014:592419.

11. Steenvoorde P, Jukema GN. The antimicrobial activity of maggots: in-vivo results. J Tissue Viability. 2004;14(3):97-101.

12. Cazander G, Pritchard DI, Nigam Y, Jung W, Nibbering PH. Multiple actions of Lucilia sericata larvae in hard-to-heal wounds: larval secretions contain molecules that accelerate wound healing, reduce chronic inflammation and inhibit bacterial infection. Bioessays. 2013:35(12):1083-92.

13. Cerovsky V, Zdarek J, Fucik V, Monincova L, Voburka Z, Bem R. Lucifensin, the long-sought antimicrobial factor of medicinal maggots of the blowfly Lucilia sericata. Cell Mol Life Sci. 2010;67(3):455-66.

14. Andersen AS, Sandvang D, Schnorr KM, Kruse T, Neve S, Joergensen B, et al. A novel approach to the antimicrobial activity of maggot debridement therapy. J Antimicrob Chemother. 2010;65(8):1646-54.

15. Altincicek B, Vilcinskas A. Septic injury-inducible genes in medicinal maggots of the green blow fly Lucilia sericata. Insect Mol Biol. 2009;18(1):119-25.

16. Huberman L, Gollop N, Mumcuoglu KY, Block C, Galun R. Antibacterial properties of whole body extracts and haemolymph of Lucilia sericata maggots. J Wound Care. 2007;16(3):123-7.

17. Kawabata T, Mitsui H, Yokota K, Ishino K, Oguma K, Sano S. Induction of antibacterial activity in larvae of the blowfly Lucilia sericata by an infected environment. Med Vet Entomol. 2010;24(4):375-81.

18. Beasley WD, Hirst G. Making a meal of MRSA-the role of biosurgery in hospital-acquired infection. J Hosp Infect. 2004;56(1):6-9.

19. van der Plas MJ, van der Does AM, Baldry M, Dogterom-Ballering HC, van Gulpen C, van Dissel JT, et al. Maggot excretions/secretions inhibit multiple neutrophil pro-inflammatory responses. Microbes Infect. 2007:9(4):507-14.

20. van der Plas MJ, Baldry M, van Dissel JT, Jukema GN, Nibbering PH. Maggot secretions suppress pro-inflammatory responses of human monocytes through elevation of cyclic AMP. Diabetologia. 2009;52(9):1962-70.

21. Mumcuoglu KY, Ingber A, Gilead L, Stessman J, Friedmann R, Schulman H, et al. Maggot therapy for the treatment of intractable wounds. Int J Dermatol. 1999;38(8):623-7.

22. Mumcuoglu KY. Clinical applications for maggots in wound care. Am J Clin Dermatol. 2001;2(4):219-27.

23. Prete PE. Growth effects of Phaenicia sericata larval extracts on fibroblasts: mechanism for wound healing by maggot therapy. Life Sci. 1997:60(8):505-10.

24. Honda K, Okamoto K, Mochida Y, Ishioka K, Oka M, Maesato K, et al. A novel mechanism in maggot debridement therapy: protease in excretion secretion promotes hepatocyte growth factor production. Am J Physiol Cell Physiol. 2011:301(6):C1423-30.

25. Zarchi K, Jemec GB. The efficacy of maggot debridement therapy-a review of comparative clinical trials. Int Wound J. 2012;9(5):469-77.

26. Cooper DM, Yu EZ, Hennessey P, Ko F, Robson MC. Determination of endogenous cytokines in chronic wounds. Ann Surg. 1994;219(6):688-91. discussion 91-2.

27. Pierce GF, Tarpley JE, Tseng J, Bready J, Chang D, Kenney WC, et al. Detection of platelet-derived growth factor (PDGF)-AA in actively healing human wounds treated with recombinant PDGF-BB and absence of PDGF in chronic nonhealing wounds. J Clin Invest. 1995:96(3):1336-50.

28. Braund R, Hook S, Medlicott NJ. The role of topical growth factors in chronic wounds. Curr Drug Deliv. 2007:4(3):195-204.

29. Heldin $\mathrm{CH}$, Westermark B. Mechanism of action and in vivo role of plateletderived growth factor. Physiol Rev. 1999;79(4):1283-316.

30. Siegfried G, Basak A, Prichett-Pejic W, Scamuffa N, Ma L, Benjannet S, et al. Regulation of the stepwise proteolytic cleavage and secretion of PDGF-B by the proprotein convertases. Oncogene. 2005;24(46):6925-35. 
31. Papanas N, Maltezos E. Becaplermin gel in the treatment of diabetic neuropathic foot ulcers. Clin Interv Aging. 2008;3(2):233-40.

32. Pierce GF, Tarpley JE, Allman RM, Goode PS, Serdar CM, Morris B, et al. Tissue repair processes in healing chronic pressure ulcers treated with recombinant platelet-derived growth factor BB. Am J Pathol. 1994;145(6): 1399-410.

33. Kumar A, Verma A, Mishra A, Agrawal G, Agrawal A, Mishra S. Platelet derived growth factor in healing of large diabetic foot ulcers in Indian clinical set-up: a protocol-based approach. WebmedCentral Wound Heal. 2013;4(2):WMC003985.

34. Embil JM, Papp K, Sibbald G, Tousignant J, Smiell JM, Wong B, et al. Recombinant human platelet-derived growth factor-BB (becaplermin) for healing chronic lower extremity diabetic ulcers: an open-label clinical evaluation of efficacy. Wound Repair Regen. 2000;8(3):162-8.

35. Steed DL. Clinical evaluation of recombinant human platelet-derived growth factor for the treatment of lower extremity diabetic ulcers. Diabetic Ulcer Study Group. J Vasc Surg. 1995;21(1):71-8. discussion 9-81.

36. Steed DL. Clinical evaluation of recombinant human platelet-derived growth factor for the treatment of lower extremity ulcers. Plast Reconstr Surg. 2006;117(7 Suppl):143S-9S. discussion 50S-51S.

37. Rees RS, Robson MC, Smiell JM, Perry BH. Becaplermin gel in the treatment of pressure ulcers: a phase II randomized, double-blind, placebo-controlled study. Wound Repair Regen. 1999;7(3):141-7.

38. Hardikar JV, Reddy YC, Bung DD, Varma N, Shilotri PP, Prasad ED, et al. Efficacy of Recombinant Human Platelet- Derived Growth Factor (rh-PDGF) based gel in diabetic foot ulcers: a randomized, multicenter, double- blind, placebo- controlled study in India. Wounds. 2005;17(6):141-52.

39. Wieman TJ, Smiell JM, Su Y. Efficacy and safety of a topical gel formulation of recombinant human platelet-derived growth factor-BB (becaplermin) in patients with chronic neuropathic diabetic ulcers. A phase III randomized placebo-controlled double-blind study. Diabetes Care. 1998;21(5):822-7.

40. Smiell JM, Wieman TJ, Steed DL, Perry BH, Sampson AR, Schwab BH. Efficacy and safety of becaplermin (recombinant human platelet-derived growth factor-BB) in patients with nonhealing, lower extremity diabetic ulcers: a combined analysis of four randomized studies. Wound Repair Regen. 1999; 7(5):335-46

41. Nagai MK, Embil JM. Becaplermin: recombinant platelet derived growth factor, a new treatment for healing diabetic foot ulcers. Expert Opin Biol Ther. 2002;2(2):211-8.

42. Wieman TJ. Clinical efficacy of becaplermin (rhPDGF-BB) gel. Becaplermin Gel Studies Group. Am J Surg. 1998;176(2A Suppl):74S-9S.

43. Senet P, Vicaut E, Beneton N, Debure C, Lok C, Chosidow O. Topical treatment of hypertensive leg ulcers with platelet-derived growth factor-BB: a randomized controlled trial. Arch Dermatol. 2011;147(8):926-30.

44. Ma C, Hernandez MA, Kirkpatrick VE, Liang LJ, Nouvong AL, Gordon II. Topical platelet-derived growth factor vs placebo therapy of diabetic foot ulcers offloaded with windowed casts: a randomized, controlled trial. Wounds. 2015:27(4):83-91.

45. Concha C, Edman RM, Belikoff EJ, Schiemann AH, Carey B, Scott MJ. Organization and expression of the Australian sheep blowfly (Lucilia cuprina) hsp23, hsp24, hsp70 and hsp83 genes. Insect Mol Biol. 2012;21(2):169-80.

46. Sze SH, Dunham JP, Carey B, Chang PL, Li F, Edman RM, et al. A de novo transcriptome assembly of Lucilia sericata (Diptera: Calliphoridae) with predicted alternative splices, single nucleotide polymorphisms and transcript expression estimates. Insect Mol Biol. 2012;21(2):205-21.

47. Concha C, Belikoff EJ, Carey BL, Li F, Schiemann AH, Scott MJ. Efficient germ-line transformation of the economically important pest species Lucilia cuprina and Lucilia sericata (Diptera, Calliphoridae). Insect Biochem Mol Biol. 2011:41(1):70-5

48. Li F, Wantuch HA, Linger RJ, Belikoff EJ, Scott MJ. Transgenic sexing system for genetic control of the Australian sheep blow fly Lucilia cuprina. Insect Biochem Mol Biol. 2014;51:80-8

49. Lobo N, Li X, Fraser Jr MJ. Transposition of the piggyBac element in embryos of Drosophila melanogaster, Aedes aegypti and Trichoplusia ni. Mol Gen Genet. 1999:261(4-5):803-10.

50. Guerrero FD, Dowd SE, Djikeng A, Wiley G, Macmil S, Saldivar L, et al. A database of expressed genes from Cochliomyia hominivorax (Diptera: Calliphoridae). J Med Entomol. 2009;46(5):1109-16.

51. Scott MJ. Development and evaluation of male-only strains of the Australian sheep blowfly, Lucilia cuprina. BMC Genet. 2014;15 Suppl 2:S3.
52. van Oers MM, Pijlman GP, Vlak JM. Thirty years of baculovirus-insect cell protein expression: from dark horse to mainstream technology. J Gen Virol. 2015;96(Pt 1):6-23.

53. Medin JA, Hunt L, Gathy K, Evans RK, Coleman MS. Efficient, low-cost protein factories: expression of human adenosine deaminase in baculovirusinfected insect larvae. Proc Natl Acad Sci U S A. 1990;87(7):2760-4.

54. Fossgreen A, Bruckner B, Czech C, Masters CL, Beyreuther K, Paro R. Transgenic Drosophila expressing human amyloid precursor protein show gamma-secretase activity and a blistered-wing phenotype. Proc Natl Acad Sci U S A. 1998;95(23):13703-8.

55. O'Connell KP, Kovaleva E, Campbell JH, Anderson PE, Brown SG, Davis DC, et al. Production of a recombinant antibody fragment in whole insect larvae. Mol Biotechnol. 2007:36(1):44-51.

56. Kato T, Kajikawa M, Maenaka K, Park EY. Silkworm expression system as a platform technology in life science. Appl Microbiol Biotechnol. 2010;85(3): 459-70.

57. Michaud S, Marin R, Tanguay RM. Regulation of heat shock gene induction and expression during Drosophila development. Cell Mol Life Sci. 1997;53(1): 104-13.

58. Matsumoto S, Tanaka R, Okada K, Arita K, Hyakusoku H, Miyamoto M, et al The effect of control-released basic fibroblast growth factor in wound healing: histological analyses and clinical application. Plast Reconstr Surg Glob Open. 2013;1(6):e44.

59. Moore AJ, Beazley WD, Bibby MC, Devine DA. Antimicrobial activity of cecropins. J Antimicrob Chemother. 1996;37(6):1077-89.

60. Ali RA, Mellenthin K, Fahmy K, Da Rocha S, Baumgartner S. Structural conservation of the salivary gland-specific slalom gene in the blowfly Lucilia sericata. Dev Genes Evol. 2005;215(10):537-43.

61. Elliott DA, Brand AH. The GAL4 system : a versatile system for the expression of genes. Methods Mol Biol. 2008;420:79-95.

62. Singh B, Crippen TL, Zheng L, Fields AT, Yu Z, Ma Q, et al. A metagenomic assessment of the bacteria associated with Lucilia sericata and Lucilia cuprina (Diptera: Calliphoridae). Appl Microbiol Biotechnol. 2015;99(2):869-83.

63. Hurwitz I, Fieck A, Read A, Hillesland H, Klein N, Kang A, et al. Paratransgenic control of vector borne diseases. Int J Biol Sci. 2011:7(9):1334-44.

64. Thomas S, Jones M, Wynn K, Fowler T. The current status of maggot therapy in wound healing. Br J Nurs. 2001:10(22 Suppl):S5. -8, S10, S2.

65. Steenvoorde P, Buddingh TJ, van Engeland A, Oskam J. Maggot therapy and the "yuk" factor: an issue for the patient? Wound Repair Regen. 2005; 13(3):350-2.

66. Grassberger M, Fleischmann W. The biobag - a new device for the application of medicinal maggots. Dermatology. 2002;204(4):306.

67. Blancke S, Van Breusegem F, De Jaeger G, Braeckman J, Van Montagu M. Fatal attraction: the intuitive appeal of GMO opposition. Trends Plant Sci. 2015;20(7):414-8.

68. BM S, Gao S, Zhu N, Sudlow GP, Liang K, Som A, et al. Binocular Goggle Augmented Imaging and Navigation System provides real-time fluorescence image guidance for tumor resection and sentinel lymph node mapping. Sci Rep. 2015;5:12117.

69. Dorsett-Martin WA. Rat models of skin wound healing: a review. Wound Repair Regen. 2004;12(6):591-9.

70. Li F, Vensko 2nd SP, Belikoff EJ, Scott MJ. Conservation and Sex-Specific Splicing of the transformer Gene in the Calliphorids Cochliomyia hominivorax, Cochliomyia macellaria and Lucilia sericata. PLoS One. 2013; 8(2):e56303.

71. Li X, Heinrich JC, Scott MJ. piggyBac-mediated transposition in Drosophila melanogaster: an evaluation of the use of constitutive promoters to control transposase gene expression. Insect Mol Biol. 2001;10:447-55.

72. Edman RM, Linger RJ, Belikoff EJ, Li F, Sze SH, Tarone AM, et al. Functional characterization of calliphorid cell death genes and cellularization gene promoters for controlling gene expression and cell viability in early embryos. Insect Mol Biol. 2015;24(1):58-70.

73. Oku H, Shimizu T, Kawabata T, Nagira M, Hikita I, Ueyama A, et al. Antifibrotic action of pirfenidone and prednisolone: different effects on pulmonary cytokines and growth factors in bleomycin-induced murine pulmonary fibrosis. Eur J Pharmacol. 2008;590(1-3):400-8. 